\title{
Our anesthesia experience in a patient with goldenhar-gorlin syndrome
}

\begin{abstract}
Childrens with congenital anomalies affecting the airway can pose a significant challenge for the anesthesia management. In Goldenhar-Gorlin syndrome, anomalies that may lead to difficulty in intubation anomaly may occur. Difficult or impossible laryngoscopy has been described in Goldenhar- Gorlin syndrome patients. The aim of this case report is to attract attention to this syndrome which fulfills many criteria for difficulty of intubation.
\end{abstract}

Keywords: goldenhar syndrome, airway management, difficult intubation
Volume 2 Issue 4 - 2015

\author{
Ozkan Onal, Emine Cepni Kutahya, Oguzhan \\ Arun, Ates Duman \\ Department of Anesthesia and Intensive Care, Selçuk University \\ Medical Faculty, Turkey
}

Correspondence: Ozkan Onal, Department of Anesthesiology and Reanimation, Selcuk University Faculty of Medicine, Konya, Turkey,Tel+905059052252, Email drozkanonal@selcuk.edu.tr

Received: May 06, 2015 | Published: June 18, 2015

\section{Introduction}

Goldenhar-Gorlin syndrome was defined by Goldenhar in 1952 and redefined by Gorlin et al.. ${ }^{1}$ in 1963 as auriculo-vertebral syndrome. Goldenhar syndrome is a rare oculo-auriculo-vertebral syndrome occurring at the stage of blastogenesis resulting from 1 and 2 branchial arch anomaly. It occurs every 1/3500-1/5600 births. Male/ female ratio is: $3 / 2 .^{2}$ Goldenhar-Gorlin syndrome is characterized by ear anomalies, hemifacial microsomia, cardiac anomalies and vertebral colon anomalies. In this syndrome, anomalies that may lead to difficulty in intubation such as facial asymmetry, large forehead, micrognatia, cleft palate, hemifacial hyoplasia, malocclusion and vertebral anomaly may occur. The aim of this case report is to attract attention to this syndrome which fulfills many criteria for difficulty of intubation. ${ }^{3,4}$

\section{Case}

A 9year old patient at the weight of $30 \mathrm{~kg}$ and who was diagnosed with Goldenhar-Gorlin syndrome was planned to undergo meatoplasty operation by otorhinolaryngology department. In the anesthesia evaluation prior to operation, it was learned that he had no chronic disease and known allergy other than the syndrome. In preoperative evaluation, the following features of the syndrome were present: facial symmetry, preauricular tag, epibulbar dermoid, right maxillofacial hyoplasia and right mandibular hypoplasia, torticollis, scoliosis, membranous ventricular septal defect anomalies which were reported to have closed previously and gastroesophageal reflux. Head and neck movements were slightly restricted due to torticollis and overall Wilson risk score was 2 (weight: 0 , head-neck movements: 1 , jaw movement: 0 , jaw structure: 1 , teeth structure: 0 ). In the anesthesia evaluation made before operation, it was learned that he underwent operation when he was 7 months old due to urachus cysts and at the age of 2 due to adenotonsillectomy. No information could be obtained regarding anesthesia techniques used during these operations. Laboratory findings and lung graphy findings were normal except for scoliotic minimal curve in thoracal vertebrae. As the patient fulfilled the criteria of difficult intubation, prior to operation airways, ventilation masks, endotracheal tubes, Miller and Macintosh blades appropriate to the child's age were prepared. Patient was transferred to operating theater and routine monitorization was performed. The patient was agigated, and induction was initiated with sevofloran ve $\mathrm{N}_{2} \mathrm{O}$ and vascular access was establihed. $10 \mathrm{mg}$ Rocuronium (Esmeron, Organone, Hollande) was administered because of its fast effect. After ventilation with mask, he was intubated without any problem with gum intubation catheter (Frova, Cook, USA). Anesthesia was maintained with the mixture of $60 \% \mathrm{~N}_{2} \mathrm{O}$ and $2.5 \%$ sevofloran. Following the operation lasting one hour, spontaneous respiration returned and after $0.3 \mathrm{mg}$ atropin and $1.2 \mathrm{mg}$ neostigmine were administered, patient was extubated and sent to clinic without any complications.

\section{Discussion}

In patients with Goldenhar-Gorlin syndrome, the presence of craniofacial and vertebral anomalies increases the risk of difficult airway. In addition, whether operation is carried out under emergency or elective conditions is important for securing airway. ${ }^{5}$ In the evaluation made in the patients with Goldenhar-Gorlin syndrome, scoliosis, micrognatia and restriction of extension are risk factors for the probability of difficulty of intubation. Therefore one must be ready for nasal laryngeal mask, fiber optic intubation, and if necessary tracheostomy. These patients may also experience ventilation problems due to decrease in functional and residual capacity and total lung capacity accompanied by hemifacial hypoplasia. Moreover, a patient with Goldenhar-Gorlin syndrome may also have obstructive sleep apnea commonly. Altıntaş F \& Cakmakkaya OS. ${ }^{6}$ decided to intubate a 4year old patient with Goldenhar-Gorlin syndrome who will undergo ectropion surgery without muscle relaxants and administered propofol (Propofol, Fresenius, Turkey) $(2.0 \mathrm{mg} / \mathrm{kg}$ ) and remifentanil (Ultiva, Glaxo SmithKline,Turkey) $(1 \mu \mathrm{gr} / \mathrm{kg})$ as anesthetic. They did not encounter any problems in anesthesia induction when they were not successful at first attempt with Macintosh 2 blade, they passed to Miller 2 blade and attempted intubation with $4.5 \mathrm{~mm}$ tracheal tube. They did not succeed at first attempt, but tube number was made smaller $(4 \mathrm{~mm})$ and intubation attempt was repeated with the help of intubation stile and with success this time. In the maintenance of anesthesia $\% 1$ sevofloran was used with mixture of $\% 50 \mathrm{O}_{2} / \mathrm{N}_{2} \mathrm{O}$ and anesthesia was completed without complication, not using any muscle relaxants. In the present study, propofol was not preferred as it is still controversial in pediatric age group before the age of 3 , and for anesthesia induction, midazolam $(0.1 \mathrm{mg} / \mathrm{kg})$ and fentanyl $(1 \mu \mathrm{gr} / \mathrm{kg})$ were used. Kabalak et al. ${ }^{7}$ attempted blind intubation in a 6month year old patient planned to undergo operation for congenital 
hip dislocation using muscle relaxants and were successful at second attempt via an intubation tube sent as a guide to oesephagus. Jones et al. ${ }^{8}$ used laryngeal mask for securing airway in all of the 43 patients with Goldenhar-Gorlin syndrome between the ages of 23 months - 14years who were anesthesized for the implanting of hearing device and emphasized that laryngeal mask provides easy, safe and rapid anesthesia without leading to trauma. Sukhupragam $\mathrm{W} \&$ Rosenblatt $\mathrm{WH}^{9}$ preoxygenized a 10year old patient, who was planned to undergo keratoplasty and predicted to have difficulty in airway and then deepened the anesthesia with sevofloran induction the concentration of which they increased gradually. In order to facilitate airway manipulation, flexible laryngeal mask was placed readily using $50 \mathrm{mg}$ propofol. For maintenance of anesthesia, they used $30 \% \mathrm{O}_{2} / 70 \% \mathrm{~N}_{2} \mathrm{O}$ mixture with $2 \%$ sevofloran and did not employ muscle relaxants in any stage of anesthesia and as analgesic they used overall $30 \mu \mathrm{gr}$ fentanyl with intervals. Alternative airway devices developed in parallel to the advances in technology facilitated the job of anesthesists, increasing the safety of both the patients and the anesthesist. Milne et al. ${ }^{10}$ reported that in a 9 year old girl with Goldenhar-Gorlin sydrome who will be submitted to general anesthesia for ear debridement and tooth extraction, when they were not successful in direct laryngoscopy which they attempted without muscle relaxants by using $8 \%$ sevofloran induction and intermittent propofol $(2 \mathrm{mg} / \mathrm{kg})$, they obtained images at adequate quality after a few attempts with a video laryngoscopy method called glidescope and managed to intubate the patient. Özlü et al.. ${ }^{11}$ reported that, in a 6 year old child with Goldenhar-Gorlin syndrome planned to undergo operation for posterior fossa decompression and occipitocervical fusion after premedication with, midazolam $(7 \mathrm{mg})$, nasal topical anesthetics were administered and patient was intubated at the first attempt with fiberoptic bronchoscopy. Maintenance of anesthesia was made with desfluran $50 \% / 50 \% \mathrm{O}_{2}$ /air mixture using muscular relaxant $(0.1 \mathrm{mg} / \mathrm{kg}$ vecuronium). Although awake intubation is gold standard in patients who are estimated to have airway difficulty, this is not possible in pediatric patients as it may lead to airway anomalies. ${ }^{9}$ In the present patient predicted to have airway difficulty, mask ventilation and intubation was carried out successfully at first attempt, which relieved us and obviated the need for alternative airway techniques.

\section{Conclusion}

As the intubation is highly likely to be difficult in such patients, a thorough preoperative evaluation is required. It is our suggestion that adequate monitorisation should be carried out, anesthesia technique and equipment and technique should be determined in advance and necessary preparations is made for successful intubation and intubation stile can be used for difficult intubation.

\section{Acknowledgements}

None.

\section{Conflicts of interest}

The authors declare that there are no conflicts of interest.

\section{Funding}

None.

\section{References}

1. Mohandessan MM, Romano PE. Neuroparalytic keratitis in GoldenharGorlin syndrome. Am J Ophthal. 1978;85(1):111-113.

2. Palmisano BW, Rusy LM. Anesthesia for plastic surgery. In:Gregory GA, Editors. Pediatric anesthesia. (4th edn.) Churchill Livingstone, New York, USA, pp. 707-745.

3. Epstein CL. Genetic Disorders and Birth Defects. In: Rudolph AM, et al. Editors. Rudolph's Pediatrics. 20 $0^{\text {th }}$ edn. Stamford CT: Appleton \& Lange; 1996. pp. 249-265.

4. Madan R, Trikha A, Venkataraman RK, et al. Goldenhar's syndrome: analysis of anesthetic management. A retrospective study of seventeen cases. Anaesthesia. 199045(1):49-52.

5. Nijhawan N, Morad Y, Seigel-Bartelt J, et al. Car uncle abnormalities in the oculo-vertebral spectrum. Am J Med Genet. 2002;15(113):320-325.

6. Altintas F, Cakmakkaya OS. General anesthesia for a child with Goldenhar sydrome. Pediatric Anesthesia. 2005;15(6):529-530.

7. Kabalak A, Pehlivan VF, Akçay F, et al. Goldenhar sendromlu olguda zor entübasyon:Olgu sunumu. Turkiye Klinikleri J Anest Reanim. 2004;2(2):83-86.

8. Jones SE, Dickson U, Moriarty A. Anesthesia for insertion of bone anchored hearing aids in children: 7-year audit. Anestesia. 2001;56(8):777-780.

9. Sukhupragam W, Rosenblatt WH. Airway management in a patient with Goldenhar syndrome:a case report. J Clin Anesth. 2008;20(3):214-217.

10. Milne AD, Dower AM, Hackmann T. Airway management using the pediatric Glide Scope in a child with Goldenhar syndrome and atypical plasma cholinesterase. Paediatr Anaesth. 2007;17(5):484-487.

11. Özlü O, Şimşek S, Alaçakır H, et al. Goldenhar syndrome and intubation with the fiber optic broncoscope. Paediatr Anaesth. 2008;18(8):793794 